\title{
Influencia del tratamiento enzimático en la calidad de aceites vegetales
}

\author{
Por J. Sineiro', H. Domínguez ${ }^{2}$ y M. J. Núñez ${ }^{1}$ \\ 'Departamento de Enxeñería Química. Universidad de Santiago de Compostela. Avda. das Ciencias, s/n. \\ 15706 Santiago de Compostela. \\ ${ }^{2}$ Departamento de Enxeñería Química. Universidad de Vigo (Campus Ourense). \\ As Lagoas. 32004 Ourense.
}

\section{RESUMEN}

Influencia del tratamiento enzimático en la calidad de aceites vegetales

En este estudio se revisan los efectos del tratamiento enzimático, aplicado con el fin de mejorar la extractabilidad del aceite, sobre la calidad y pureza de aceites comestibles extraídos de vegetales. Se presentan aspectos relativos a la estabilidad y refinabilidad de aceites de semillas y de aceite de oliva y otros frutos, asi como la valoración organoléptica de este último. Los aceites obtenidos por aplicación de tecnología enzimática muestran composición y características similares a los obtenidos de materiales sin tratar.

PALABRAS-CLAVE: Aceite vegetal - Calidad - Enzima Revisión (artículo).

\section{SUMMARY}

Influence of the enzymatic treatment on the quality of vegetable oils

In this paper the effects of the enzymatic treatment on the quality and composition of vegetable edible oils are revised. Stability and refinability related aspects of oils from seeds, olive and other fruits are presented, so as an organoleptic valoration of the olive oil. Oils from enzyme aided processes show composition and characteristics similar to the ones from oils obtained from raw materials.

KEY-WORDS: Enzyme - Quality - Review (paper) Vegetable oil.

\section{INTRODUCCIÓN}

La aplicación del tratamiento enzimático durante los procesos de extracción de aceites vegetales permite elevar los rendimientos de extracción y mejorar la calidad nutricional de las harinas. El empleo de enzimas como auxiliares tecnológicos en la extracción de aceites vegetales podría representar una nueva perspectiva de desarrollo para las industrias del sector debido a las condiciones suaves durante el procesado, lo que mantiene la calidad del aceite y la proteína (Caragay, 1983; Graille et al., 1988; Domínguez et al., 1994).

Para lograr la extracción de aceite, que se encuentra en vacuolas intracelulares, han de romperse las paredes y membranas celulares. El tratamiento mecánico y térmico causa esta rotura de las estructuras celulares, pero en ocasiones no es suficiente y parte del aceite permanece sin extraer. Las actividades celulolítica y hemicelulolítica son las más adecuadas para degradar la pared vegetal, pues éstos son los polisacáridos mayoritarios de la misma; las pectinasas también son efectivas puesto que las sustancias pécticas son componentes estructurales de materiales vegetales, responsables de la coherencia e integridad de los tejidos. Las mezclas de enzimas y los complejos de actividad múltiple son mâs éficaces que los enzimas purificados (Fullbrook, 1984; Olsen, 1986; Bathnagar y Johari, 1987; Montedoro y Petruccioli, 1974) aunque el efecto resultante no es la suma de los individuales (Dusterhoft et al., 1993).

Las principales fuentes vegetales de aceite son las semillas y frutos oleaginosos. La diferente composición y estructura de ambas condiciona el distinto procesado al que se someten con el fin de extraer el aceite. Por el desarrollo que ha alcanzado la industria procesadora y por la calidad del aceite obtenido merece destacarse, sobre todo en el área mediterránea la extracción del aceite de oliva.

El proceso estándar de extracción de frutos consiste en un batido con agua caliente y posterior separación de las fases líquida:(acuosa/oleosa) y sólida por distintos procedimientos (prensado, centrifugación...). Algunas pastas de oliva presentan dificultades durante su extracción (pastas «fluentes» o «difíciles»), que se ponen de manifiesto con retención y oclusión de las fases líquidas en la pasta, el aceite emulsionado, fugas de sólidos y por lo tanto menor rendimiento de extracción de aceite. Los enzimas se han incorporado con éxito al procesado de la oliva, aumentando los rendimientos, y se han empleado con éxito a escala laboratorio, piloto e industrial (Santos, 1978; Alba et al., 1987a y b; Montedoro y Petruccioli, 1973; Cintra et al., 1986; Siniscalco y Montedoro, 1988; Sosulski y Sosulski, $1990 \mathrm{a}, \mathrm{b})$.

El proceso de extracción de aceite de semillas depende del tipo y estructura de las mismas. Con las de bajo contenido graso ( $<20 \%$ ib.s.) se emplea la extracción con disolventes orgánicos (hexano), usada también para extraer el aceite residual de la torta 
resultante de extraer por presión semillas de elevado contenido graso. Las principales desventajas de los procesos de extracción convencionales, definidos para maximizar la extracción del aceite, son aspectos ambientales y de seguridad, así como los efectos indeseables sobre la calidad de los productos que podrían causar las elevadas temperaturas alcanzadas en determinadas etapas. Los procesos alternativos de extracción plantean el uso de disolventes biorrenovables siendo el agua el más estudiado, obteniéndose aceite de buena calidad y un producto proteico libre de factores tóxicos o antinutritivos (Rhee et al., 1972, Hagenmaier, 1974; Hagenmaier et al., 1973; Lawhon et al., 1981; Gresch, 1989). El proceso es análogo al descrito para los frutos. Puesto que el agua no es un disolvente específico del aceite la eficacia de extracción es baja.

El tratamiento enzimático puede incorporarse a la extracción de aceite de frutos o al procesado acuoso de semillas sin excesivos cambios en el proceso pues las condiciones operacionales (contenido en agua, $\mathrm{pH}$, temperatura y agitación) durante el batido son compatibles con los valores óptimos para la acción enzimática. En ambos casos se mejora significativamente el rendimiento, aunque generalmente el incremento alcanzado es considerablemente mayor para la extracción de aceite de semillas debido a los reducidos valores alcanzados con agua como disolvente extractor. Puede realizarse eliminando totalmente el uso de disolventes orgánicos (Lanzani et al., 1975; Marek et al., 1990; Domínguez et al., 1995 a, b; Tano-Debrah et al., 1995 a y b), en presencia de hexano (Fullbrook, 1983 y 1984), o añadiendo hexa- no para facilitar la recuperación del aceite (Badr y Sitohy, 1992; Sengupta y Battacharyya, 1996). La incorporación dúrante el procesado convencional (prensádo y/o disolvente) podría incrementar la productividad o reducir el tiempo de operación con mínimas alteraciones en el proceso en curso. Se han encontrado aumentos en el rendimiento de extracción y/o mayor velocidad de extracción con diferentes semillas (Sosulski et al., 1988; Sosulski y Sosulski, 1990b; Smith et al., 1993; Domínguez et al., 1993; Domínguez et al., 1996).

Por su distinta naturaleza y proceso extractivo, a continuación se hace un estudio independiente del aceite de oliva y del de otros frutos y semillas. Además, puesto que la aplicación de tecnología enzimática a la extracción de aceite de oliva se ha estudiado desde hace dos décadas, se dispone de mayor número de datos procedentes de escala laboratorio, piloto e industriàl:

\section{ACEITE DE OLIVA}

En la Tabla I se presenta un resumen de los distintos enzimas empleados para la extracción del aceite de oliva, así como el aumento de rendimiento logrado con respecto a muestras sin tratar. Se presentan valores alcanzados durante el procesado en laboratorio, planta piloto e industrial mediante extracción por centrifugación y de una única etapa de presión. Leone et al., (1977) también ofrecen resultados de segunda presión, pero el aumento de rendimiento es inapreciable y no se indica.

Tabla 1

Incremento del rendimiento de extracción de aceite de oliva tratada con enzimas

\begin{tabular}{|c|c|c|c|}
\hline Actividad Enzimática Principal & Extracción & Rdto. & Referencia \\
\hline Pectinasa & centrifugación & $1.8(7.4)^{\star \star}$ & Siniscalco y Montedoro (1988) \\
\hline Pectinasa-celulasa & presión única & $1.8(7.0)^{\star \star \star}$ & Leone et al., (1977) \\
\hline \multirow{3}{*}{ Pectinglicosidasa-celulasa-hemicelulasa } & centrifugación & $1.6(3.8)$ & Alba et al., (1987b) \\
\hline & presión única & $1.1(3.7)^{\star \star \star}$ & Alba et al., (1987b) \\
\hline & $\begin{array}{l}\text { centrifug. } \\
\text { continua }\end{array}$ & $1.7(8.3)^{\star \star}$ & Alba et al., (1987a) \\
\hline \multirow[t]{2}{*}{ Pectinasa-hemicelulasa-polisacaridasa } & $\begin{array}{l}\text { centrifug. } \\
\text { continua }\end{array}$ & $2.0(9.9)^{\star \star}$ & Alba et al., (1990) \\
\hline & presión única & $1.38(7.0)^{\star \star \star}$ & Alba et al., (1990) \\
\hline Pectinasa-celulasa & presión única & $3.8(15.0)$ & Santos $(1978)$ \\
\hline Pectinasa + celulasa + papaína & presión única & $3.0(11.7)^{\star \star}$ & Montedoro y Petruccioli (1973) \\
\hline Celulasa + pectinasa & presión única & $2.1(8.0)^{\star \star \star}$ & - Montedoro y Petruccioli (1974) \\
\hline Celulasa + proteasa & presión única & $2.0(7.7)$ & Montedoro et al., (1975) \\
\hline
\end{tabular}

* Diferencia entre el rendimiento de extracción de las pastas tratadas y no tratadas en $\mathrm{kg}$ aceite/100 kg fruto, (porcentaje del total extraído con enzimas-porcentaje del total extraído sin enzimas).

** Piloto o semipiloto, *** industrial. 
Los máximos aumentos que se consiguen están en torno a $3 \mathrm{~g}$ de aceite/100 $\mathrm{g}$ de oliva ( $11 \%$ sobre el total de aceite extraíble). Aunque estos valores pueden parecer bajos, representan un considerable valor económico. Debe mencionarse además que las cantidades de enzima utilizadas son bajas $(10-30 \mathrm{~g} / 100 \mathrm{~kg})$.

Composición. En la Tabla II se presenta la composición de aceite de oliva obtenido con tecnología enzimática por diversos autores y no se observan diferencias significativas con el extraído sin aplicación de enzimas.

Calidad. En la Tabla III se resumen algunas características del aceite obtenido de muestras control así como de muestras tratadas con enzimas de diversas actividades enzimáticas (celulasas, hemicelulasas, pectinasas, proteasas o con mezclas de los mismos), extraídas por centrifugación, presión única o percola- ción, procediendo casi todos los datos de procesos industriales. Los valores indicados en esta Tabla permiten comparar el efecto del tratamiento enzimático sobre la calidad de los aceites, pero deben tomarse con cautela los datos procedentes de diversos autores, pues emplean distintas variedades de aceituna. Así, los datos de Montedoro y Petruccioli (1973) se refieren a las variedades Moraiolo y Frantoio, mientras que los de Alba et al., (1987 b, 1990) corresponden a las variedades Hojiblanca, Verdial, Lechín o Picual. Además del grado de acidez se comparan otras características como peróxidos (medida de oxidabilidad), insaponificable, estabilidad y absorbancia en el ultravioleta mediante los índices $\mathrm{K}_{232}$ y $\mathrm{K}_{270}$ (medidas respectivas de los hidroperóxidos y de las diacetonas, cetonas alfa insaturadas y otros grupos oxigenados que indican la extensión de la oxidación).

Tabla II

Composición de aceites de oliva obtenidos con tecnología enzimática

\begin{tabular}{lcccccccccc}
\hline & \multicolumn{3}{c}{ Montedoro et al., (1975) } & Duarte y Sameiro (1979) & \multicolumn{3}{c}{ Alba et al., (1990) } \\
\cline { 2 - 10 } & \multicolumn{3}{c}{ M, F } & \multicolumn{2}{c}{ G } & \multicolumn{3}{c}{ H, L, P, V } \\
\cline { 2 - 10 } & Control & C+PC & C+PR & Control & PC-C & Control & PGL-C-H & Control & PC-H-PS \\
\cline { 2 - 10 } C-14 (mirístico) & & & & trazas & trazas & trazas & trazas & 0.01 & 0.01 \\
C-16 (palmítico) & 10.85 & 10.90 & 10.90 & 14.0 & 14.1 & 8.6 & 8.7 & 7.5 & 7.6 \\
C-16:1 (palmitoleico) & 0.70 & 0.58 & 0.58 & 2.3 & 2.3 & 0.6 & 0.6 & 0.7 & 0.6 \\
C-17 (margárico) & 0.25 & 0.25 & 0.25 & 0.2 & 0.2 & - & - & - & - \\
C-17:1 (margaroleico) & - & - & - & 0.4 & 0.3 & - & - & - & - \\
C-18 (esteárico) & 1.80 & 1.95 & 1.92 & 1.9 & 2.0 & 3.4 & 3.3 & 2.7 & 3.0 \\
C-18:1 (oleico) & 79.55 & 79.50 & 79.50 & 73.9 & 73.8 & 77.9 & 77.8 & 76.9 & 76.6 \\
C-18:2 (linoleico) & 6.05 & 6.00 & 6.00 & 5.2 & 5.4 & 7.6 & 7.6 & 8.8 & 8.7 \\
C-18:3 (linolénico) & 0.50 & 0.42 & 0.40 & 1.2 & 1.1 & 0.6 & 0.6 & 0.7 & 0.7 \\
C-20:1 (gadoleico) & 0.20 & 0.30 & 0.35 & 0.4 & 0.3 & trazas & trazas & 0.5 & 0.5 \\
C-22:0 (araquídico) & - & - & - & 0.1 & 0.1 & $-\cdots$ & - & - & - \\
C-22:1 (erúcico) & - & - & - & - & - & trazas & trazas & 0.1 & 0.1 \\
\hline
\end{tabular}

Enzima:

C: celulasa; H: hemicelulasa; PC: pectinasa; PGL: pectinglucosidasa; PR: proteasa; PS: polisacaridasa.

Variedad oliva:

F: Frantoio, M: Moraiolo, G: Gallega, H: Hojiblanca; L: Lechín, P: Picual, V: Verdial. 
Tabla III

Características de aceites de oliva provenientes de muestras control o tratadas con distintos enzimas, y obtenidos con diversos métodos de extracción

\begin{tabular}{|c|c|c|c|c|c|c|c|c|c|c|c|c|c|c|c|}
\hline \multirow[b]{3}{*}{ Acidez $\left(^{\star}\right)$} & \multicolumn{2}{|c|}{$\begin{array}{l}\text { Centrifugación } \\
\text { (laboratorio) }\end{array}$} & \multicolumn{4}{|c|}{ Centrifugación } & \multicolumn{5}{|c|}{ Presión única } & \multicolumn{4}{|c|}{ Percolación } \\
\hline & Control & PGL-C.H & Control & PGL-C-H & Control & PC-HPS & Control & $P G+P R+C$ & Control & $\mathrm{C}+\mathrm{PC}$ & C+PR & Control & PG & $P G+P R$ & $P G+P R+C$ \\
\hline & 0.4 & 0.3 & 0.32 & 0.28 & 0.23 & 0.22 & 0.74 & 0.55 & 1.10 & 1.66 & 1.23 & 0.86 & 0.55 & 0.55 & 0.67 \\
\hline Humedad (\%) & - & - & 0.21 & 0.11 & 0.17 & 0.16 & - & 一 & - & - & - & 一 & - & - & - \\
\hline Impurezas (\%) & - & - & 0.04 & 0.09 & 0.04 & 0.05 & 一 & - & - & - & - & - & - & - & - \\
\hline Peróxidos (meq/kg) & 5.7 & 9.4 & 9.40 & 10.50 & 16.30 & 19.10 & 19.96 & 19.38 & 15.50 & 12.80 & 15.50 & 19.34 & 23.87 & 22.30 & 24.39 \\
\hline Estabilidad A.O.M. (h) & 47.5 & 48.1 & 42.00 & 40.92 & 26.75 & 24.45 & 11.58 & 11.25 & 11.8 & 12.45 & 12.52 & 9.00 & 10.25 & 11.00 & 10.67 \\
\hline Insaponificable (\%) & - & - & 0.77 & 0.74 & 1.16 & 1.10 & - & - & - & - & - & - & - & - & - \\
\hline $\mathrm{K}_{232}$ & - & - & 1.73 & 1.62 & - & - & 1.88 & 1.72 & 2.32 & 2.35 & 2.35 & 1.84 & 1.76 & 1.88 & 1.84 \\
\hline \multirow{3}{*}{$\begin{array}{l}K_{270} \\
\text { Variedad aceituna }\end{array}$} & 0.19 & 0.18 & 0.15 & 0.13 & 0.11 & 0.15 & 0.175 & 0.130 & 0.140 & 0.210 & 0.190 & 0.178 & 0.160 & 0.185 & 0.160 \\
\hline & \multicolumn{2}{|c|}{$\mathrm{H}$} & \multicolumn{4}{|c|}{$H, L, P, V$} & \multicolumn{2}{|c|}{$M, F$} & \multicolumn{3}{|c|}{$\mathrm{M}, \mathrm{F}$} & \multicolumn{4}{|c|}{$M, F$} \\
\hline & \multicolumn{2}{|c|}{$\begin{array}{l}\text { Alba et al., } \\
\text { (1987b) }\end{array}$} & \multicolumn{4}{|c|}{ Alba et al., (1990) } & \multicolumn{2}{|c|}{$\begin{array}{c}\text { Montedoro y } \\
\text { Petruccioli (1973) }\end{array}$} & \multicolumn{3}{|c|}{$\begin{array}{l}\text { Montedoro et al., } \\
\text { (1975) }\end{array}$} & \multicolumn{4}{|c|}{$\begin{array}{c}\text { Montedoro y } \\
\text { Petruccioli (1973) }\end{array}$} \\
\hline
\end{tabular}

C: celulasa; H: hemicelulasa; PC: pectinasa; PG: poligalacturonasa; PGL: pectinglucosidasa; PR: proteasa; PS: polisacaridasa.

F: Frantoio, M: Moraiolo, H: Hojiblanca; L: Lechín, P: Picual, V: Verdial.

En cuanto a la acidez, ésta es en general ligeramente menor en los aceites de muestras tratadas. Los valores de acidez son sensiblemente mayores en aceites procedentes de presión y de percolación. Montedoro y Petruccioli (1973) justifican èsta diferencia debido a la adición de tampón conteniendo $\mathrm{NaOH}$, que neutraliza parte de los ácidos grasos liberados, mientras que las pastas a las que no se ha añadido tampón y han sido extraídas por centrifugación presentan un aumento del contenido en ácidos grasos libres. A pesar de la mayor acidez de los aceites de prensa en comparación con los de separación en continuo, el sabor de estos últimos resulta perjudicado, pues se endurece con un predominio amargo, debido a la presencia de taninos (Totosaus, 1990). El contenido en peróxidos de los aceites de muestras tratadas es en general ligeramente mayor que en los de olivas no tratadas, (Montedoro y Petruccioli, 1973; Montedoro et al., 1975; Leone et al., 1977). La estabilidad oxidativa (método del oxigeno activo, A.O.M), tiempo en horas para alcanzar un índice de peróxidos igual a 100 , ofrece unos valores que indican que el tratamiento enzimático no afecta sensiblemente a este parámetro. Los valores son diferentes según el procesado de los aceites, pues a medida que se fuerzan las condiciones extractivas (presión y separación en continuo) disminuye la estabilidad, observándose externamente una mayor intensidad de color. Algunos autores (Leone et al, 1977) relacionan la estabilidad con el contenido en polifenoles del aceite.
Respecto a características externas, Montedoro et al., (1975) y Duarte y Sameiro (1979) observaron mayor transparencia en los aceites procedentes de tratamiento enzimático frente a los de olivas no tratadas (Figura 1). Al iguall que :estos autores, Albá et al., (1987a, b y 1990) observaron que los aceites procedentes de olivas tratadas presentaron siempre mejor aspecto y limpieza que los obtenidos de las muestras control, sin apreciarse diferencias significativas respecto a las determinaciones convencionales de calidad, pureza, composición y características organolépticas.

Estabilidad. En la Tabla IV se presenta una medida de la diferente resistencia a la oxidación de aceites de oliva obtenidos tras la primera y segunda etapas de presión, así como de los aceites de presión única, empleando variedad Coratina, que había mostrado mayor susceptibilidad al aumento de rendimiento por acción del tratamiento enzimático.

Los: aceites obtenidos por procedimiento de primera presión y los de presión única mostraron mayor resistencia a la autooxidación que los aceites de segunda presión. En éstos, el número de peróxido es netamente superior y el contenido en polifenoles sensiblemente inferior. La influencia de la aplicación del tratamiento enzimático no sigue una tendencia definida, registrándose el mayor aumento del número de peróxido en los aceites obtenidos tras una única etapa de presión. 


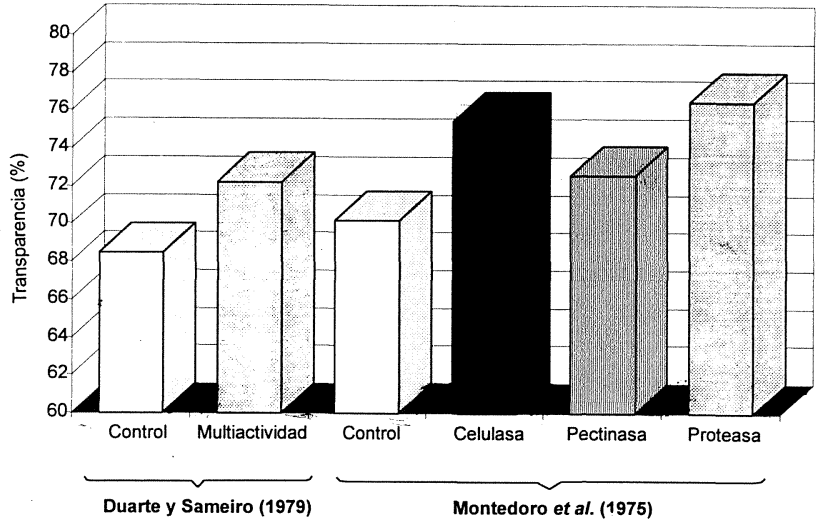

Figura 1

Efecto del tratamiento enzimático sobre la transparencia del aceite de oliva (Montedoro et al., 1975; Duarte y Sameiro, 1979).

Cabe destacar el elevado contenido en tocoferoles del aceite de segunda presión. La protección antioxidante si atendemos a la suma tocoferoles+polifenoles es ligeramente superior en los aceites de presión única; los bajos valores de polifenoles en los aceites de segunda presión quedarían compensados por el contenido en tocoferoles. También el contenido en esteroles, que son alcoholes superiores monovalentes que interfieren en la absorción intestinal del colesterol es similar en aceites de primera presión y presión única y no hay diferencia entre los obtenidos con y sin tratamiento enzimático (Tabla V).

En las Figuras $2 a$ y $2 b$ se muestran algunos parámetros de calidad de aceite de oliva y su evolución durante un año de conservación. Se aprecia un mantenimiento del grado de acidez en aceites obtenidos con y sin tecnología enzimática, siendo siempre inferiores los contenidos en los aceites obtenidos de muestras tratadas con enzimas. Respecto a las características organolépticas, cabe destacar la mejor puntuación obtenida por los aceites de muestras tratadas enzimáticamente, sobre todo a tiempos largos. No se detectaron diferencias organolépticas significativas en períodos de hasta 120 días, pero sí a partir de estos tiempos, siendo entonces los aceites tratados con enzimas los preferidos por los catadores. El color de los aceites, tanto los procedentes de muestras tratadas como los de aquéllas no tratadas, se mantiene constante en un tono amarillo-verdoso. Se observa una mayor estabilidad a lo largo del tiempo en las muestras procedentes de olivas tratadas con enzimas. El contenido en peróxidos aumenta de modo más acusado en las muestras procedentes de olivas control, de modo que a partir de 120 días es mayor que en el de muestras de olivas tratadas enzimáticamente.

Tabla IV

Resistencia a la autooxidación del aceite de primera, segunda presión y de presión única, medida como número de peróxidos, y contenido en tocoferoles y polifenoles (Leone et al., 1977). $1 \mathrm{~g}$ celulasa+pectinasa/ $100 \mathrm{~kg}$ oliva variedad Coratina

\begin{tabular}{lcccccc}
\hline & \multicolumn{2}{c}{ Primera presión } & \multicolumn{2}{c}{ Segunda presión } & \multicolumn{2}{c}{ Presión única } \\
\cline { 2 - 7 } & Control & Enzima & Control & Enzima & Control & Enzima \\
\cline { 2 - 7 } & 6.3 & 5.1 & 12.1 & 11.6 & 6.9 & 8.1 \\
Número de peróxidos & 18.6 & 18.8 & 37.0 & 37.2 & 20.3 & 20.2 \\
Tocoferoles (mg/100 g aceite) & 20.3 & 21.2 & 8.0 & 6.5 & 25.1 & 25.3 \\
\hline Polifenoles (mg/100 g aceite) & & & &
\end{tabular}

Tabla V

Composición en esteroles (mg\%) del aceite de oliva (Leone et al., 1977). $1 \mathrm{~g}$ celulasa+pectinasa/100 $\mathrm{kg}$ oliva variedad Coratina

\begin{tabular}{lccccccc}
\hline & \multicolumn{2}{c}{ Primera presión } & \multicolumn{2}{c}{ Segunda presión } & \multicolumn{2}{c}{ Presión única } \\
\cline { 2 - 7 } & Control & Enzima & Control & Enzima & Control & Enzima \\
\cline { 2 - 7 } & 3.6 & 3.7 & 6.0 & 5.2 & 3.9 & 3.9 \\
Campesterol & 0.6 & 0.8 & 1.8 & 0.8 & 0.4 & 0.4 \\
Stigmasterol & 110.0 & 109.9 & 206.0 & 203.3 & 110.0 & 116.0 \\
Bsitosterol & tr & 0.6 & tr & tr & tr & tr \\
$\Delta_{7}$ Stigmasterol & & & & & &
\end{tabular}



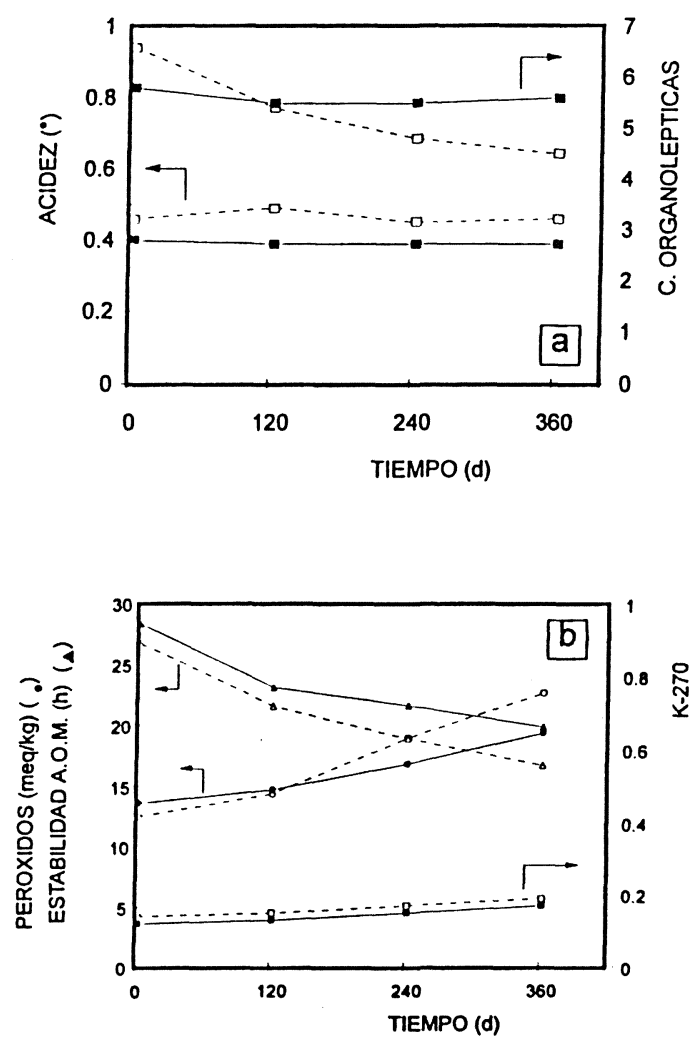

Figura 2

Evolución de (a) acidez y valoración organoléptica, así como de (b) estabilidad, contenido en peróxidos e índice K-270 de aceites de oliva de muestras control (símbolo hueco) y tratadas con enzimas (símbolo lleno) (Alba et al., 1990).

\section{ACEITE DE FRUTOS Y SEMILLAS}

En la Tabla VI se resumen los aumentos de rendimiento de extracción de aceite de frutos y semillas obtenidos por efecto del tratamiento enzimático (referido a muestras control sobre el total de aceite extraíble). Aunque podrían parecer valores muy elevados, en comparación con los registrados con aceite de oliva, debe ponerse de manifiesto que la mayoría son datos de laboratorio, muchas veces con procesos extractivos que implican disolventes orgánicos, y en algunos casos en condiciones no extrapolables a la operación real, pues la única finalidad es la constatación de la acción enzimática. Los mayores aumentos se registran en el proceso acuoso, debido posiblemente a la menor eficacia de eliminación de aceite del proceso base. Puesto que los resultados proceden de distintos trabajos experimentales realizados con diferente variedad de semillas y en diferentes condiciones operacionales, no se puede realizar una comparación rigurosa de los valores obtenidos. Así durante la extracción acuosa asistida por disolventes orgánicos, los resultados obtenidos por Fullbrook (1984) durante la extracción de aceite de colza y soja cuando no se aplica tratamiento en- zimático revelan que sólo se extrae un 12.5 y $13.6 \%$ del aceite total extraíble respectivamente, mientras que Bhatnagar y Johari (1987) con un proceso experimental similar registran un incremento "extra» del aceite obtenido respecto a las condiciones control, en las que prácticamente se extrae todo el aceite contenido en las semillas.

Composición. Los autores reseñados en la Tabla VII comparan composiciones de aceites tratados, bien con valores estándar, bien con los aceites comerciales. En todo caso los valores se encuentran siempre en el rango establecido en la norma de calidad de cada uno de los aceites. La composición de los aceites obtenidos por procesamiento enzimático es similar al de aceites provenientes de frutos y semillas no tratados.

Calidad. En la Tabla VIII se muestran algunos de los parámetros habituales de calidad del aceite, así como el procedimiento de extracción en cada caso y las condiciones del tratamiento enzimático (Temperatura, ${ }^{\circ} \mathrm{C}$ / humedad, \%/cantidad de enzima, g/100 g/tiempo de incubación, h). En cada semilla se puede comparar el valor con los valores estándar o bien con un control, no detectándose en general grandes diferencias. Merecen destacarse los valores de fosfolípidos obtenidos tras el tratamiento enzimático de soja y de colza. Se observa un pronunciado aumento en los aceites crudos obtenidos tras la aplicación de tecnología enzimática.

Procesado acuoso. Olsen (1987) encontró que el aceite de colza procedente de un proceso enzimático llevado a cabo en planta piloto presentaba la misma composición en ácidos grasos y un contenido en A.G.L. y peróxidos superior al del material crudo. Fullbrook (1984) comparó los parámetros de calidad del aceite de colza obtenido en un proceso de extracción acuosa asistida por enzimas con los valores estándar, comprobando que se encontraban dentro de los límites establecidos. Laiho et al., (1991) compararon aceites provenientes del tratamiento con diferentes enzimas usando como referencia el proceso de extracción en Soxhlet. Cabe destacar el bajo contenido en fosfolípidos del aceite obtenido por procesado acuoso y el ligeramente menor contenido en clorofila. Este comportamiento también fue observado por Bocevska et al., (1993) con aceite de germen de maiz. Tano-Debrah y Ohta (1995b) observaron que el contenido en A.G.L. y peróxidos disminuía en aceites procedentes de tratamiento enzimático durante el procesado acuoso respecto al de muestras control y al extraído con hexano.

Los aceites de girasol obtenidos empleando enzimas durante el procesado acuoso no presentaron valores de densidad ni de índice de refracción significativamente diferentes a los de muestras control, presentando los àceites obtenidos tras el tratamiento con celulasas propiedades más similares a las muestras control (Sitohy et al., 1993).

El aceite obtenido tras el procesado acuoso presenta siempre color claro:y'transparente, generalmente no requiere la etapa de desgomado siendo suficiente un desodorizado para hacerlo apto para uso alimentario. 
Tabla VI

Incremento del rendimiento de extracción de aceite de frutos y semillas tratados con enzimas

\begin{tabular}{|c|c|c|c|}
\hline \multicolumn{4}{|c|}{ Procesado acuoso } \\
\hline Semilla/Fruto & Actividad principal & Incrmto.* & Referencia \\
\hline \multirow[t]{2}{*}{ Aguacate } & $\alpha$-amilasa & 68 & Buenrostro y López-M. (1986) \\
\hline & Mezcla de $\alpha$-amilasa y proteasa & 65 & Buenrostro y López-M. (1986) \\
\hline \multirow[t]{2}{*}{ Cacahuete } & Mezcla de proteasa y celulasa & 6 & Lanzani et al., (1975) \\
\hline & Mezcla de pectinasa, proteasa y celulasa & 6 & Lanzani et al., (1975) \\
\hline \multirow[t]{6}{*}{ Coco } & Mezcla de pectinasa y $\alpha$-amilasa & 46.9 & Cintra et al., (1986) \\
\hline & Mezcla de pectinasa, $\alpha$-amilasa y proteasa & $68 / 62.7^{\star \star}$ & Cintra et al., (1986) \\
\hline & Multiactividad + galactomananasa & 57 & Christenson y Olsen (1989) \\
\hline & Proteasa + celulasa + hemicelulasa & 8.4 & Tano-Debrah y Ohta, (1995 b) \\
\hline & Celulasa + amilasa + poligalacturonasa & 17.82 & Che Man et al., (1996) \\
\hline & $\begin{array}{l}\text { Celulasa + amilasa + poligalacturonasa + } \\
\text { proteasa }\end{array}$ & 22.41 & Che Man et al., (1996) \\
\hline \multirow[t]{3}{*}{ Colza } & Mezcla de pectinasa y proteasa & 35 & Lanzani et al., (1975) \\
\hline & Amilasa, $\beta$ glucanasa y nproteasa & 31 & Fullbrook (1984) \\
\hline & Celulasa ( $A$. terreus) & 11 & Marek et al., (1990) \\
\hline Germen maiz & Celulasa (A. terreus) & 54 & Marek et al., (1990) \\
\hline Germen trigo & Celulasa & 40 & Hitze et al., (1972) \\
\hline \multirow[t]{7}{*}{ Girasol } & Celulasa & 14 & Lanzani et al., (1975) \\
\hline & Pectinasa & 14 & Lanzani et al., (1975) \\
\hline & Mezcla de pectinasa y celulasa & 22 & Lanzani et al., (1975) \\
\hline & Celulasa y hemicelulasa & 20 & Badr y Sitohy, (1992) \\
\hline & Pectinasa & 22 & Badr y Sitohy, (1992) \\
\hline & Celulasa + pectinasa & 26.35 & Domínguez et al., (1995a) \\
\hline & Actividad múltiple & 24.53 & Domínguez et al., (1995a) \\
\hline \multirow[t]{2}{*}{ Mostaza } & Celulasa & 47.5 & Szakácz-Dobozi et al., (1988) \\
\hline & Celulasa + pectinasa & 22.8 & Sengupta y Bhattacharyya, (1996) \\
\hline Salvado de arroz & Celulasa + pectinasa & 28 & Sengupta y Bhattacharyya, (1996) \\
\hline \multirow[t]{3}{*}{ Soja } & Amilasa, $\beta$ glucanasa y nproteasa & 33 & Fullbrook (1984) \\
\hline & Celulasa ( $P$. verruculosum) & 8 & Marek et al., (1990) \\
\hline & Actividad múltiple & 7 & Domínguez et al., (1995b) \\
\hline \multirow[t]{2}{*}{ Karité } & Proteasa, celulasa y hemicelulasa & 24 & Tano-Debrah y Ohta, (1995a) \\
\hline & Proteasa, celulasa y hemicelulasa & 11.34 & Tano-Debrah et al.; (1996) \\
\hline
\end{tabular}

* Aumento del rendimiento de extracción (porcentaje de aceite total recuperado) cuando se emplean enzimas frente al proceso sin enzimas.

** Medido como incremento de rendimiento de extracción.

p: Prensado discontinuo a 3- $107 \mathrm{~N} / \mathrm{m} 2$ durante $20 \mathrm{~min}$; p": prensado discontinuo a $7.5 .10^{7} \mathrm{~N} / \mathrm{m}^{2}$ durante 5 minutos.

$\mathrm{h}$ : Extracción en Soxhlet con hexano durante $4 \mathrm{~h}$; $\mathrm{p}^{\prime \prime}$ : extracción con hexano, $30 \mathrm{C}$. 
Tabla VI

(Continuación)

\begin{tabular}{|c|c|c|c|}
\hline \multicolumn{4}{|c|}{ Procesado acuoso asistido con disolvente ${ }^{\star *}$} \\
\hline Semilla & Actividad principal & Incrmto. ${ }^{*}$ & Referencia \\
\hline \multirow[t]{2}{*}{ Ricino } & Celulasa & 3.11 & Bhatnagar y Johari (1987) \\
\hline & Hemicelulasa & 2.92 & Bhatnagar y Johari (1987) \\
\hline \multirow[t]{2}{*}{ Algodón } & Celulasa & 3.62 & Bhatnagar y Johari (1987) \\
\hline & Hemicelulasa & 3.57 & Bhatnagar y Johari (1987) \\
\hline \multirow[t]{2}{*}{ Girasol } & Celulasa & 3.21 & Bhatnagar y Johari (1987) \\
\hline & Hemicelulasa & 3.10 & Bhatnagar y Johari (1987) \\
\hline \multirow[t]{3}{*}{ Colza } & $\alpha$-amilasa, $\beta$ glucanasa y nproteasa & 16.10 & Fullbrook (1984) \\
\hline & Pectinasa-celulasa & 17.70 & Fullbrook (1984) \\
\hline & Hemicelulasa & 18.30 & Fullbrook (1984) \\
\hline \multirow[t]{3}{*}{ Soja } & Celulasa & 2.99 & Bhatnagar y Johari (1987) \\
\hline & Pectinasa-celulasa & 13.90 & Fullbrook (1984) \\
\hline & Hemicelulasa & 15.10 & Fullbrook (1984) \\
\hline \multicolumn{4}{|c|}{ Procesado convencional (presión y/o disolventes) } \\
\hline Semilla & Actividad principal & Incrmto.* & Referencia \\
\hline Colza & Múltiple & 12.53 & Sosulki et al., (1988) \\
\hline (Canola) & Pectinasa & 7.42 & \\
\hline Colza & Bioglucanasa & 29 & Zúñiga et al., (1991) \\
\hline \multirow[t]{2}{*}{ Girasol } & Celulasa + Pectinasa & $\begin{array}{l}13.1 p \\
10 h\end{array}$ & Domínguez et al., (1996) \\
\hline & Actividad combinada & $\begin{array}{l}11.8 p \\
4 h\end{array}$ & Dominguez et al., (1996) \\
\hline \multirow[t]{2}{*}{ Soja } & Celulasa no comercial & $\begin{array}{l}21.4 p^{\prime \prime} \\
6.4 \mathrm{~h}\end{array}$ & Smith et al., (1993) \\
\hline & Celulasa & $\begin{array}{l}10 " \\
6 "\end{array}$ & Dominguez et al., (1995b) \\
\hline
\end{tabular}

* Aumento del rendimiento de extracción (porcentaje de aceite total recuperado) cuando se emplean enzimas frente al proceso sin enzimas.

** Medido como incremento de rendimiento de extracción.

p: Prensado discontinuo a 3- $107 \mathrm{~N} / \mathrm{m} 2$ durante $20 \mathrm{~min}$; p": prensado discontinuo a $7.5 .10^{7} \mathrm{~N} / \mathrm{m}^{2}$ durante $5 \mathrm{minutos}$.

h: Extracción en Soxhlet con hexano durante 4 h; p": extracción con hexano, $30 \mathrm{C}$.

Procesado por presión y/o disolventes. Sosulski y Sosulski (1990b) observaron que la digestión enzimática de las paredes celulares incrementa los niveles de fosfolípidos en el aceite. Tanto las celulasas como las pectinasas causan un aumento de más del doble en el contenido en fosfolípidos, sin embargo los enzimas más eficaces aumentan sólo marginalmente este contenido. También las celulasas causan un importante incremento en el contenido en clorofila de los aceites, como se indica en la tabla. 
Tabla VII

Composición de aceites de frutos y semillas obtenidos con tecnología enzimática

\begin{tabular}{|c|c|c|c|c|c|c|c|c|c|c|c|c|c|}
\hline & \multicolumn{2}{|c|}{$\begin{array}{c}\text { Coco } \\
\text { (Christenson \& Olsen, 1989) }\end{array}$} & \multicolumn{2}{|c|}{$\begin{array}{c}\text { Colza } \\
\text { Olsen, } 1987\end{array}$} & \multicolumn{4}{|c|}{$\begin{array}{c}\text { Girasol } \\
\text { (Sitohy et al., 1993) }\end{array}$} & \multicolumn{3}{|c|}{$\begin{array}{c}\text { Mostaza } \\
\text { (Sengupta y Bhattacharya, 1996) }\end{array}$} & \multicolumn{2}{|c|}{$\begin{array}{c}\text { Salvado de arroz } \\
\text { (Sengupta y Bhattacharyya, } 1996\end{array}$} \\
\hline & & Estándar & & Estándar & Celulasa & Proteasa & Pectinasa & Hexano & $\begin{array}{c}\text { Comercial } \\
\text { (Prensado) }\end{array}$ & Soxhlet & $\begin{array}{l}\text { Celulasay } \\
\text { pectinasa }\end{array}$ & $\begin{array}{l}\text { Comercial } \\
\text { (Disolvte.) }\end{array}$ & $\begin{array}{l}\text { Celulasay } \\
\text { pectinasa }\end{array}$ \\
\hline C-8 (caprilico) & 7.61 & 7 & - & - & - & 0.00 & trazas & trazas & - & - & - & - & - \\
\hline C-10 (decanoico) & 6.36 & 7 & - & - & - & - & - & - & - & - & - & - & - \\
\hline C-12 (laurico) & 49.5 & 45 & - & 0.1 & 2.91 & 1.54 & 2.81 & 2.81 & - & - & - & - & - \\
\hline C-14 (miristico) & 18.9 & 20 & 1.3 & 0.1 & 0.12 & 0.81 & trazas & 0.09 & 0.3 & - & - & $0.3-0.6$ & 0.3 \\
\hline C-16 (palmítico) & 8.68 & 8 & 4.5 & $2-7$ & 3.10 & 4.11 & 3.72 & 3.08 & $2-5$ & 23.7 & 1.9 & $16-24$ & 24.2 \\
\hline C-16:1 (palmitoleico) & 0.15 & - & 0.2 & 1 & - & - & - & - & - & - & - & - & - \\
\hline C-18 (esteárico) & 3.07 & 3 & 1.7 & $1-3$ & 11.08 & 11.32 & 11.71 & 10.23 & $0.4-1.2$ & 1.6 & 0.4 & $1-3$ & 1.6 \\
\hline C-18:1 (oleico) & 4.90 & 7 & 57.7 & $50-65$ & 43.06 & 44.04 & 49.12 & 44.12 & $9-14$ & 43.4 & 10.2 & $40-48$ & 43.1 \\
\hline C-18:2 (linoleico) & 0.84 & 2 & 20.2 & $15-30$ & 38.01 & 35.07 & 29.97 & 31.11 & $14-20$ & 30.1 & 16.8 & $30-35$ & 30.0 \\
\hline C-18:3 (linolénico) & - & - & 10.9 & $6-14$ & - & - & - & - & $9-17$ & 0.2 & 12.7 & $0.2-0.8$ & 0.2 \\
\hline C-20:0 (aráquico) & - & - & - & - & - & - & - & - & - & 0.6 & - & $0.5-1.0$ & 0.6 \\
\hline C-20:1 (gadoleico) & - & - & 0.6 & 4.5 & - & - & - & - & $6-8$ & - & 6.5 & - & - \\
\hline C-22:1 (erúcico) & - & - & 1.4 & 5 & - & - & - & - & $45-54$ & - & 51.3 & - & - \\
\hline
\end{tabular}

Refinabilidad. Únicamente se publicaron resultados con aceite de canola. Se observa que la mayor parte de los fosfolípidos son no hidratables, y tras una etapa de refinado ácido es posible eliminar sobre el $92 \%$ de los mismos en aceites de variedad Westar.

El desgomado con agua de los aceites obtenidos con tecnología enzimática permite la eliminación del $25-53 \%$ de los fosfolípidos (medidos como fósforo), siendo mayor la reducción alcanzada en los aceites extraídos tras el tratamiento con SP-249 que con Olease (ambas preparaciones enzimáticas con diversas actividades) (Figura 3). Los contenidos en A.G.L. y clorofila decrecen ligeramente durante el desgomado acuoso.

Estabilidad. Los estudios realizados sobre aceite de canola mostraron que tanto los aceites pro- venientes de semillas tratadas con enzima como los de las no tratadas presentan patrones de comportamiento similar frente a la rancidez oxidativa, evaluada a $60^{\circ} \mathrm{C}$ en períodos de hasta 15 días. Puesto que en aceites refinados este parámetro está relacionado con el nivel de ácidos grasos no saturados (principalmente linoleico) no cabría esperar efecto debido a la aplicación del tratamiento enzimático. La Tabla IX presenta la evolución del valor de peróxidos o productos similareś de la oxidación de la grasa (medido como meq de oxígeno activo contenido en un $\mathrm{kg}$ de aceite) durante un tiempo de 15 días en muestras de aceite de distintas variedades obtenidos tras el tratamiento enzimático o sin este tratamiento. 
Tabla VIII

Comparación de las características de calidad de los aceites de frutos y semillas obtenidos con tecnología enzimática

\begin{tabular}{|c|c|c|c|c|c|c|c|c|c|}
\hline & $\begin{array}{l}\text { Condiciones } \\
\text { tratamiento }\end{array}$ & Extracción & $\begin{array}{l}\text { Peróxidos } \\
\text { (meq/kg) }\end{array}$ & $\begin{array}{l}\text { N. }{ }^{\circ} \text { lodo } \\
\text { (cg/100 g) }\end{array}$ & $\begin{array}{l}\text { A.G.L. } \\
(\%)\end{array}$ & $\begin{array}{l}\text { Fosfolípidos } \\
\text { (ppm) }\end{array}$ & Saponific & $\begin{array}{l}\text { Clorofila } \\
\text { (ppm) }\end{array}$ & Referencia \\
\hline \multicolumn{10}{|l|}{ COLZA } \\
\hline Disolvente & - & Soxhlet & 3.1 & 117.5 & 0.80 & 121.5 & - & 21.5 & Laiho et al., (1991) \\
\hline Pectinex & $45 / 80 / 2 / 24$ & Centrifugación & 10.2 & 116.0 & 0.55 & 1.8 & - & .19 .2 & Laiho et al., (1991) \\
\hline Olease & $45 / 80 / 2 / 24$ & Centrifugación & 3.9 & 115.9 & 0.82 & 1.4 & - & 14.0 & Laiho et al., (1991) \\
\hline Olease+Pectinex & $45 / 80 / 2 / 24$ & Centrifugación & 4.6 & 115.2 & 1.0 & 1.2 & - & 19.1 & Laiho et al., (1991) \\
\hline SP249+Pectinex & $45 / 80 / 2 / 24$ & Centrifugación & 7.8 & 116.1 & 0.77 & 2.9 & - & 18.4 & Laiho et al., (1991) \\
\hline Estándard & - & - & $\max 10$ & 94.120 & máx 0.6* & - & $168-181$ & - & Fullbrook (1984) \\
\hline Mezcla enzimas & $50-63 / 85 / 2 / 3$ & Centrifugación & 9.62 & 98 & $0.38^{*}$ & - & 174 & - & Fullbrook (1984) \\
\hline Control & - & Centrifugación & 1.58 & - & 1.49 & - & 171 & - & Olsen (1987) \\
\hline SP-311 & $50 / 80 / 0.5 / 4$ & Centrifugación & $2.36-2.41$ & - & $2.45-3.33$ & - & $180-182$ & - & Olsen (1987) \\
\hline Control & $50 / 30 / 0 / 6$ & Prensa continua & 1.07 & - & 0.38 & 45.8 & - & 49.4 & Sosulski \& Sosulski (1990a) \\
\hline Cellulase A & $50 / 30 / 0.1 / 6$ & Prensa continua & 1.05 & - & 0.45 & 117.1 & - & 106.9 & Sosulski \& Sosulski (1990a) \\
\hline Pectinex & $50 / 30 / 0.1 / 6$ & Prensa continua & 1.15 & - & 0.42 & 109.7 & - & 69.9 & Sosulski \& Sosulski (1990a) \\
\hline Control & $50 / 30 / 0 / 6$ & Prensa continua & 0.72 & - & 0.40 & 52 & - & 7.8 & Sosulski \& Sosulski (1993) \\
\hline Olease & $50 / 30 / 0.01 / 6$ & Prensa continua & 0.97 & - & 0.60 & 129.9 & - & 20.1 & Sosulski \& Sosulski (1993) \\
\hline Sp-249 & $50 / 30 / 0.1 / 6$ & Prensa continua & 1.00 & - & 0.63 & 110.0 & - & 17.1 & Sosulski \& Sosulski (1993) \\
\hline coco & & & & & $\cdots$ & & & & 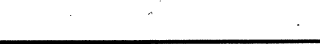 \\
\hline Estándar & & - & máx 2 & 7.5 & máx 0.05 & - & $251-264$ & - & Cintra et al., (1986) \\
\hline Poligalacturonasa & 40/75/0.1/0.3 & Centrifugación & 0.90 & 9 & 0.07 & - & 259 & - & Cintra et al., (1986) \\
\hline \multicolumn{10}{|l|}{ MOSTAZA } \\
\hline Estándar & - & Prensa & - & $98-108$ & $1-3$ & - & $170-176$ & - & Sengupta y Battacharyya, (1996) \\
\hline Disolvente & - & Soxhlet & 1.6 & 106.2 & 1.1 & - & 175.0 & - & Sengupta y Battacharyya, (1996) \\
\hline Enzima & $60 / 75 / 6 / 4$ & Hexano/centrif. & 2.0 & 106.8 & 1.3 & - & 174.3 & - & Sengupta y Battacharyya, (1996) \\
\hline \multicolumn{10}{|l|}{ GIRASOL } \\
\hline Control & $50 / 90 / 0 / 2$ & Centrifugación & 5.27 & - & 0.79 & 8.89 & 186 & - & Dominguez et al., (1995a) \\
\hline Celluclast+Pectinex & $50 / 90 / 2 / 2$ & Centrifugación & 5.12 & - & 0.82 & 7.31 & 185 & - & Dominguez et al., (1995a) \\
\hline Multifect & $50 / 90 / 2 / 2$ & Centrifugación & 5.06 & - & 0.86 & 8.26 & 186 & - & Domínguez et al., (1995a) \\
\hline Control & $50 / 25 / 0 / 6$ & Prensa discont. & 4.50 & - & 1.2 & 13.8 & 186 & - & Dominguez et al., (1996) \\
\hline Celluclast+Pectinex & $50 / 25 / 3 / 6$ & Prensa discont. & 4.30 & - & 1.4 & 16.8 & 187 & $-i$ & Domínguèz et al., (1996) \\
\hline Multifect & $50 / 25 / 3 / 6$ & Prensa discont. & 4.10 & - & 1.3 & 14.3 & 185 & - & Dominguez et al., (1996) \\
\hline \multicolumn{10}{|l|}{ KARITÉ } \\
\hline Soxhlet & - & - & 10.60 & 57.77 & 3.29 & - & 180.34 & - & Tano-Debrah y Ohta, (1995a) \\
\hline Control & $37 / 70 /-14$ & Centrifugación & 15.55 & 56.82 & 2.75 & - & 180.52 & - & Tano-Debrah y Ohta, (1995a) \\
\hline Protease (Sumizyme-AP) & $37 / 70 /-14$ & Centrifugación & 11.18 & 56.68 & 2.89 & - & 180.33 & - & Tano-Debrah y Ohta, (1995a) \\
\hline \multicolumn{10}{|l|}{ SALVADO ARROZ } \\
\hline Estándar & - & Disolvente & - & $85-105$ & máx 10 & - & $175-195$ & - & Sengupta y Battacharyya, (1996) \\
\hline Disolvente & - & Soxhlet & 2.0 & 89.4 & 3.5 & - & 184.4 & - & Sengupta y Battacharyya, (1996) \\
\hline Enzima & $60 / 75 / 6 / 4$ & Hexano/centrif. & 3.9 & 88.9 & 5.9 & - & 188.4 & - & Sengupta y Battacharyya, (1996) \\
\hline \multicolumn{10}{|l|}{ SOJA } \\
\hline Control & $50 / 20 / 0.05 / 4$ & Hexano & 3.89 & - & 0.59 & 44.0 & 190 & - & Dominguez et al., (1995b) \\
\hline Celluclast & $50 / 20 / 0.1 / 4$ & Hexano & 3.43 & - & 0.82 & 151 & 187 & - & Dominguez et al., (19.95b) \\
\hline & & & & & & & $1 x^{\prime}$ & 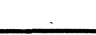 & , \\
\hline
\end{tabular}


Tabla IX

Contenido en peróxidos en aceites de canola tras el almacenamiento a $60^{\circ} \mathrm{C}$ (Sosulski y Sosulski, 1993)

\begin{tabular}{lccccccc}
\hline \multirow{2}{*}{ Variedad } & \multicolumn{7}{c}{ Peróxidos (mM/kg) } \\
\cline { 2 - 8 } & día & 0 & 3 & 6 & 9 & 12 & 15 \\
\hline Canola, Westar & Control & 0.90 & 2.59 & 3.91 & 5.11 & 7.22 & 8.19 \\
& SP-249 & 0.99 & 2.64 & 4.47 & 5.29 & 7.92 & 8.89 \\
& Olease & 0.84 & 3.01 & 4.19 & 5.71 & 8.04 & 8.97 \\
Canola, Tobin & Control & 0.79 & 3.12 & 4.84 & 5.92 & 6.93 & 7.99 \\
& SP-249 & 0.83 & 3.26 & 5.50 & 6.63 & 7.24 & 8.92 \\
Colza, Hero & Olease & 0.79 & 2.82 & 4.75 & 6.92 & 8.62 & 9.17 \\
& Control & 0.49 & 2.11 & 3.89 & 5.29 & 6.91 & 8.07 \\
& SP-249 & 0.61 & 2.47 & 3.51 & 5.40 & 7.02 & 8.11 \\
& Olease & 0.74 & 1.90 & 3.18 & 5.02 & 6.89 & 8.03 \\
\hline
\end{tabular}
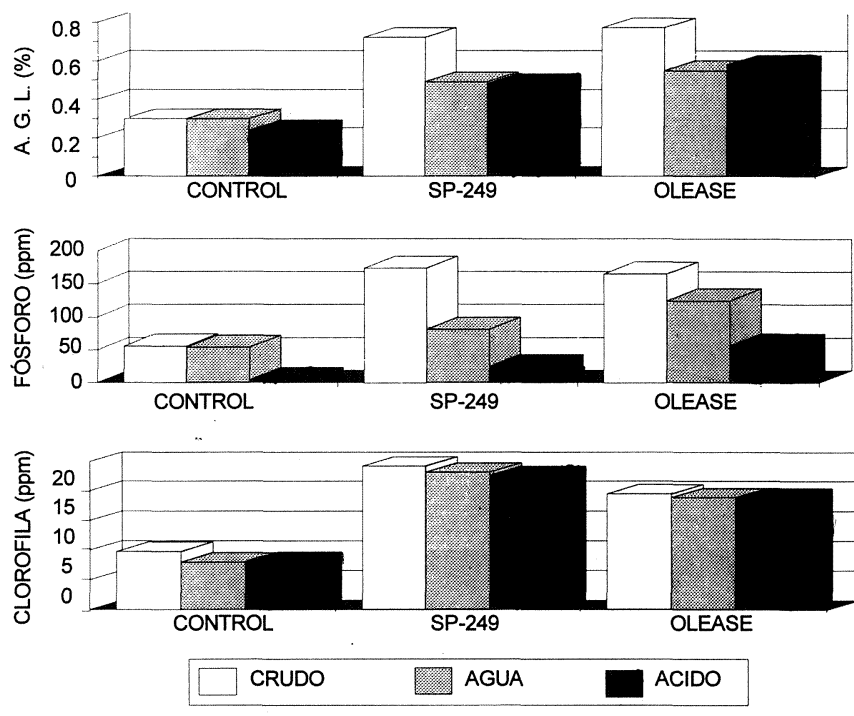

Figura 3

Efecto del tratamiento enzimático de la semilla de canola sobre la refinabilidad del aceite obtenido por presión (Sosulski y Sosulski, 1993)

\section{BIBLIOGRAFÍA}

Alba Mendoza, J., Ruíz Gómez, M.a․, Prieto González, M. ${ }^{a}$ C. y Gutiérrez Rosales F. (1987a).— «Eficacia de la formulación enzimática "Rohament O" en la tecnología del aceite de oliva. Composición y valoración organoléptica de los aceites obtenidos».-Grasas y Aceites, 38 271-277.

Alba Mendoza J., Ruíz Gómez M.ª A. y Prieto González M. ${ }^{2}$ C. (1987b).- «Estudios a nivel laboratorio e industrial sobre la utilización enzimática en la obtención del aceite de oliva».- II World Congress of Food Technology. Vol IV. Cap. V, 2885-2897.
Alba Mendoza, J., Ruíz Gómeż, A. e Hidalgo Casado, F. (1990).— «Utilización de enzimas en la extracción del aceite de oliva".-Alimentación, Equipos y Tecnología, 9, 63-71.

Badr, F. y Sitohy, M. Z. (1992).— «Optimizing conditions for enzymatic extraction of sunflower oil».-Grasas y Aceites, 43, 281-283.

Bhatnagar S. y Johari B. N. (1987).—«Microbial enzymes in the processing of oil seeds".-Current Sci., 56, 775776.

Bocevska, M., Karlovic, D., Turkulov, J. y Pericin, D. (1993)._ «Quality of corn germ oil obtained by aqueous enzymatic extraction".-J. Am. Oil Chem. Soc, 70, 1273-1277.

Buenrostro, M. y López-Munguía C., A. (1986).—«Enzymatic extraction of avocado oil».-Biotechnol. Letters, 8 505-506.

Caragay, A. (1983)._- «acing technologies in the fats and oils industry".- -J. Am. Oil Chem. Soc., 60, 1641-1644.

Cintra McGlone, O., López-Münguía C., A. y Vernon Cärter, J. (1986). - "Coconut oil extraction by a new enzymatic process".-J. Food Sci., 51, 695-697.

Che Man, Y. B., Suhardiyono, Asbi, A. B., Azudin, M. N. y Wei, L. S. (1996). - «Aqueous enzymatic extraction of coconut oil».-J. Am. Oil Chem. Soc., 73, 683-686.

Christenson, F. M. y Olsen, H. A. S. (1989).— «Method for production of an upgraded coconut product».-UK Pattent Application. GB 2215980 A.

Domínguez, H., Núñez, M. J. y Lema J. M. (1993).— «Oil extractability from enzymatically treated soybean and sunflower: range of operational variables".-Food Chem. 46, 277-284.

Domínguez H., Núñez M. J. y Lema J. M. (1994).— «Eliminación de ácido clorogénico durante el procesado acuoso de almendras de girasol».-Grasas y Aceites 44, 235-242.

Domínguez, ,H.,.Núñez, M. J. y. Lema, J. M. (1995a)."Aqueous processing of "sunflower kernels with enzymatic technology".-Food. Chem. 53, 427-434.

Domínguez, H., Núñez, M. J. y Lema, J. M. (1995b)."Enzyme-assisted hexane extraction of soya bean oil».-Food. Chem., 54, 223-231.

Domínguez, H., Núñez. M. J. y Lema. J. M. (1995c).«Procesado acuoso de soja con tecnología enzimática: extracción de aceite y producción de aislados».-Grasas y Aceites 46, 11-20. 
Domínguez, H., Sineiro, J, Núñez, M. J. y Lema, J. M. (1996). - «Enzymatic treatment of sunflower kernels before oil extraction».-Food. Res. Int. 28, 537-545.

Duarte Costa, H. M. P. de L., Sameiro, M. E. M. de M. S. (1979).— -A qualidade do azeite extraido com auxiliares tecnológicos enzimáticos".-Bol. do Instituto do Azeite e Prod. Oleaginosos 2, 25-37.

Düsterhöft, E.-M., Bonte, A. W. Venekamp, J. C. y Voragen, A. G. J. (1993).- - "The role of fungal polysaccharidases in the hydrolysis of cell wall materials from sunflower and palm-kernel meals".-World J. Microb. Biotechnol, 9, 544-554.

Fullbrook, P. D. (1983).- «The use of enzymes in the processing of oilseeds".-J. Am. Oil Chem. Soc., 60, 476-478.

Fullbrook, P. D. (1984).— «Extraction of vegetable oils. UK Patent Application» GB 2127 425A. No 8227661.

Graille J., Pina M. y Montet D. (1988).— «Biotechnology des lipids: some possible applications".-Oléagineux, 43 (4), 181-190.

Gresch, W. (1989).- -Verfahren zur gewinnug von ole und fette aus naturprodukten, und anlage zur durchfurhrung des verfahrens". C11 B 1/10, B01 D 13/00.

Hagenmaier, R. D., Cater, C. M. y Mattil, K. F. (1973)."Aqueous Processing of fresh coconuts for recovery of oil and coconut skim milk».-J. Food Sci., 38, 470-471.

Hagenmaier, R. D. (1974)._- «Aqueous Processing of full-fat sunflower seeds: yields of oil and protein".-J. Am. Oil Chem. Soc., 51, 470-471.

Hitze, W., Stute, R., Woelk, H.U., Guillaume, R. y Walon, P. (1972).— «Process for obtaining oil from oil-containing grain germs». GB Patent 1402769.

Laiho, S., Tulisalo, U., Oksanen, H. y Nystrom, R. (1991).- - A process for the production of a vegetableoil product». Int. Patent WO 91/13956.

Lanzani, A., Petrini, M. C., Cozzoli, O., Gallavresi, P., Carola, C. y Jacini G. (1975). - «On the use of enzymes for vegetable-oil extraction. A preliminary report".-La Riv. Ital. delle Sostanze Grasse, 52, 226-29.

Lawhon, J. T., Manak, L. J., Rhee, K. C. y Lusas, E. V (1981).- - «Production of oil and protein food products from raw peanuts by aqueous extraction and ultrafiltration".J. Food Sci., 46, 391-395.

Leone, A. M., Lamparelli, F., La Notte, E., Liuzzi, V. A. y Padula, M. (1977).- «L'impiego elaiotécnico di un sistema enzimatico pectocellulosolitico. Rendimento in olio a qualita del prodotto".-La Riv. Ital. delle Sostanze Grasse, 54, 514-530.

Marek, E., Schalinatus, E., Weigelt, E., Mieth, G. Kerns, G. y Kude, J. (1990). - «On the application of enzymes in the production of vegetable oil». Prog. Biotechnol, 6, 471-474.

Montedoro G. y Petruccioli G. (1973).—«Aggiornamenti sui trattamenti con additivi enzimaticci nell'estrazione dell'olio di oliva".- La Riv. Ital. delle Sostanze Grasse, 50, 331-344.

Montedoro, G. y Petruccioli, G. (1974).- «Trattamenti con additivi enzimatici e detannizzanti alle paste di olive sottoposte a processi di estrazione per pressione unica e percolamento: I. Effetti sui rendimenti in olio e su alcun parametri operativi».-La Riv. Ital. Sostanze Grasse, 51, 378-385.

Montedoro, G., Bertuccioli, M. y Petruccioli, G. (1975).«Effetti dei trattamenti con addittivi enzimatici e con detannizzanti alle paste di oliva sottoposte ad estrazione per pressione unica, sui rendimenti in olio, sulla velocita di estrazione e sulle caratteristiche analitiche degli olio, delle acque di vegetatione e delle acque residuarie».-La Riv. Ital. delle Sostanze Grasse, 52, 255-265.
Olsen, H. S. (1986).- «Enzyme Process for Extraction of rape seed oil».-Process Development Bulletin No. 2. (Novo F-865268/HSO).

Olsen, H. S. (1987).- - Aqueous enzymatic extraction of rape seed oil. Lecture given at the workshop on Agricultural Refineries -A Bridge from Farm to Industry-".Bornholm. September, 16-18. (Novo A-06008a/HSO).

Rhee, K. C., Cater, C. M. y Mattil, K. F. (1972).- «Simmultaneous recovery of protein and oil from raw peanuts in an aqueous system".-J. Food Sci., 37, 90-93.

Santos Antunes, A. F. dos (1978).— «O uso de auxiliares tecnológicos enzimáticos na extracçao do azeite».Bol. do Inst. do Azeite e Prod. Oleaginosos, 5, 39-52.

Sengupta, R. y Battacharyya, D.K. (1996).-«Enzymatic extraction of mustard seed and rice bran".-J. Am. Oil Chem. Soc., 73, 687-692.

Siniscalco V. y Montedoro, G. F. (1988)._«Estrazione meccanica dell'olio di oliva mediante l'impiego di coaduvanti tecnologici. Nota 1: drenanti ed enzimi».La Riv. Ital. delle Sostanze Grasse, 65, 675-678.

Sitohy, M. Z., Badr, E. H., Perifanova-Nemska, M., y Khadjiski, T. S. (1993). - "Characterization of enzimatically extracted sunflower seed oil as well as the protein residues».Grasas y Aceites, 44, 345-347.

Smith, D., Agrawal, Y. C., Sarkar, B. C. y Singh, B. P. N. (1993). - «Enzymatic hydrolysis pretreatment for mechanical expelling of soybeans".-J. Am. Oil Chem. Soc. 70 (9) 885-890.

Sosulski, K., Sosulski, F. W. y Coxworth, E. (1988)."Carbohydrase hydrolysis of canola to enhance oil extraction with hexane».-J. Am. Oil Chem. Soc., 65, 357-361.

Sosulski, K. y Sosulski, F. W. (1990a).- «Quality of oil and meal from enzyme treated canola seeds".-Proceedings of 33rd Annual Conference of the Canadian Institute of Food Science and Technology, 3, 656.

Sosulski, K. y Sosulski, F. W. (1990.b).— «Enzyme treatment to enhance oil extractability in canola".Ed. F. Shahidi. Rapeseed/Canola Production, Chemistry, Nutrition and Processing.

Sosulski, K. y Sosulski, F. W. (1993)._- «nzyme-aided vs. two-stage processing of canola: tecnology, product quality and cost evaluation".-J. Am. Oil Chem. Soc., 70, 825-829.

Szakács-Dobozi, M., Halász, A., Kozma-Kovács, E. y Szakács, G. (1988).- - Enhancement of mustard oil yield by cellulolytic pretreatment».-Appl. Microb. Biotechnol., 29, 39-43.

Tano-Debrah, K. y Ohta, Y. (1995a).— «Enzyme-assisted aqueous extraction of shea fat: a rural approach.-J. Am. Oil Chem. Soc., 72, 251-256.

Tano-Debrah, K. y Ohta, Y. (1995b)._ «Application of enzyme-assisted aqueous fat extraction to cocoa fat».J. Am. Oil Chem. Soc., 72, 1409-1411.

Totosaus, J. P. (1990).- «Variaciones en los parámetros de calidad del aceite, dependiendo del sistema de extracción».-Alimentación, Equipos y Tecnología, 9, 66-68.

Zúñiga, M. E., Chamy, R. y Venegas, B. (1991).-«Preparados enzimáticos para su aplicación en la industria aceitera". -9..$^{\circ}$ Congreso Nacional de Ciencia y Tecnología de los Alimentos. Santiago de Chile. Noviembre. 